\section{Original Article}

Joumal of Epilepsy Research pISSN 2233-6249 / eISSN 2233-6257

Received February 10, 2020

Revised April 21, 2020

Accepted May 21, 2020

Corresponding author:

Rita Pokharel, MSc

Department of Psychiatric Nursing, B.P.

Koirala Institute of Health Sciences, Koshi,

Dharan-18, 56700, Nepal

Tel. +9779842208006

Fax. +977025520251

E-mail; rpokharel35@gmail.com

\title{
Burden and Its Predictors among Caregivers of Patient with Epilepsy
}

\author{
Rita Pokharel, MSc ${ }^{1}$, Prakash Poudel, MD², Sami Lama, MSc ${ }^{1}$, Kriti Thapa, MSc ${ }^{1}$, \\ Rambha Sigdel, $\mathrm{MSC}^{3}$, Erina Shrestha, $\mathrm{MSC}^{4}$ \\ Departments of ${ }^{1}$ Psychiatric Nursing, ${ }^{2}$ Pediatrics and Adolescent Medicine, ${ }^{3}$ Community Health Nursing, and \\ ${ }^{4}$ Medical Surgical Nursing, B.P. Koirala Institute of Health Sciences, Dharan, Nepal
}

\begin{abstract}
Background and Purpose: Epilepsy is a chronic unpredictable debilitating condition. Epilepsy has great impacts not only on patients with epilepsies but also the persons around them. Burden among caregivers is understudied area. In view of the dearth of literature or studies focused on caregivers of children with epilepsy in Nepalese context, this study is expected to assess burden and its predictors among caregivers of children with epilepsy.
\end{abstract}

Methods: A total of 106 caregivers were interviewed using purposive sampling technique. The Zarit Burden Interview Scale short version was used to assess burden and Hospital Anxiety Depression Scale was used to assess anxiety and depression. Data were analysed using SPSS ver. 16.0. Chi-square test, multinomial logistic regression and linear regression analysis were done for analysis of inferential statistics to find out the predictors of burden.

Results: Majority of the caregivers $(71.7 \%)$ were females and $64.2 \%$ of caregivers were mothers of children. Majority of responders (77.4\%) were Hindus. Mild to moderate burden was found in $27.4 \%$ and high burden was found in $14.2 \%$ of the caregivers. Borderline anxiety, borderline depression, anxiety and depression were present in $7.5 \%, 8.5 \%, 6.6 \%$, and $6.6 \%$ caregivers respectively. Burden was significantly higher in caregivers of epileptic children with poorly controlled seizure $(p=0.003)$ and with co-morbidities $(p=0.009)$. Similarly, burden score had significant positive correlation $(p=0.001)$ with depression and significant negative correlation $(p=0.005)$ with age of onset of epilepsy in children.

Conclusions: Burden, anxiety and depression are common problems in caregivers of children with epilepsy. Poorly controlled seizure, presence of associated comorbidities, younger age of onset of seizure in children and presence of depression in caregivers are the important factors that predict burden among caregivers of children with epilepsy. (2020;10:24-30)

Key words: Epilepsy, Caregivers, Burden of illness

\section{Introduction}

Caring for children with epilepsy is a very challenging and stressful experience that is associated with significant burden and psychological morbidity among carers. Caring of children with seizure disorders is very complicated. ${ }^{1}$ Caregivers have to arrange medical appointments, handle prescription regimens and deal with the changes in their children's functioning. Parents and relatives may fear stigmatization and may not be able to maintain the balance between protective and restrictive behaviours towards their children. Caregivers may also become apprehensive, frustrated or depressed as they need to put greater effort to find sufficient and proper support for parenting a child with epilepsy. Lower education level of caregivers and increased length of time in care providing can also increase the level of burden among caregivers. ${ }^{1}$ The emotional pain experienced by them can affect the quality of care which ultimately can affect the prognosis of these patients. ${ }^{2}$ Burden of care is a multi-factorial construct which consists of emotional, psychological, physical and economic impact as well as related painful feelings such as humiliation, anger, feeling of guilt and self-blame. ${ }^{3}$ Burden can be described as objective or subjective. Objective burden refers to changes in level of functioning like household routine, family or social relations, work, leisure 
and physical health while subjective burden consists of subjective distress. ${ }^{4}$ Family caregivers have been described as hidden patients. It is reported that caregivers' symptoms such as mood swing, fatigue, headache, body ache, conflicts, and financial problems may be evidences of care giving stress. ${ }^{5}$ Burden in caregivers of patients with chronic illness like epilepsy can lead to mental health problems. This ultimately affects the compliance to treatment and overall prognosis of illness. The impact of childhood epilepsy on child's family is an overlooked issue. Given the scarcity of literature in this area, researchers sought to put a figure on psychological burden in caregivers of children and adolescents with epilepsy and to explore the factors predicting such burden.

\section{Methods}

\section{Study setting}

B.P. Koirala Institute of Health Sciences is a 750 bedded tertiary care university hospital at eastern Nepal. Most of the patients who are receiving care from this centre are from province 1 and province 2 of Nepal. A small number of patients are also from province 3 and neighbouring districts of India. Child neurology clinic is run once a week. There are about a 1,000 follow up patients currently receiving treatment from the clinic. More than $80 \%$ of them have epilepsy. There are many ethnic groups (castes) in Nepal. Nepalese caste system is the traditional system of birth ascribed social stratification and ranking of people based upon occupation of their ancestors during ancient times. The caste system is linked with education, occupation and overall socioeconomic status of people. In Nepal lower castes/ethnicities are generally socio-economically disadvantaged groups. Brahmin and Chhetri are considered as higher caste whereas Janajati is a relatively disadvantaged group. Madhesi is also considered as a disadvantaged group. Dalit and religious minorities are lower caste and marginalized people.

\section{Study participants}

Caregivers of children with epilepsy were the study participants. Caregivers were either parents or family relatives of the children. Caregivers who denied informed consent, who were under treatment for psychiatric problems and who could not communicate in Nepali language were excluded. All caregivers presenting to paediatric neurology clinic for treatment of their children during the study period were screened for eligibility. A total of 200 caregivers were screened for eligi- bility during the data collection period (from October 2018 to October 2019). Among them, 94 caregivers were excluded. Twenty-three caregivers reported psychiatric problems, 51 caregivers denied consent to participate and 20 caregivers were unable to communicate in Nepali language because they were exclusively using traditional ethnic language. Remaining eligible consenting caregivers were further interviewed to collect data.

\section{Design}

This was a cross sectional study. Diagnosis and classification of epilepsies were done by paediatric neurologist following the International League Against Epilepsy (ILAE) guidelines. ${ }^{6}$ Description of the epileptic event, videos provided by caregivers and investigation reports such as electroencephalogram and neuroimaging were used for diagnosis and classification of epilepsy. Co-morbidities were diagnosed by the paediatric neurologist and a psychologist where necessary, on the basis of Diagnostic and statistical manual of mental disorder fifth revision. Seizure was considered as well controlled when a patient remained seizure free either for at least 3 months or for two times the length of usual pre-treatment inter-ictal interval, whichever was longer. If this could not be achieved despite using two antiepileptic medicines in combination, seizure was considered as poorly controlled.

\section{Data collection tools}

Zarit Burden Interview short version scale (ZBI-12) was used to assess burden among caregivers. ${ }^{7}$ It consists of 12 items, each having a score range from 0 to 4 . The highest obtainable score is 48 . ZBI-12 classifies scores 0 to 10 as 'no to mild burden', 10 to 20 as 'mild to moderate burden' and scores above 20 as 'high burden'. 7

The Hospital Anxiety Depression Scale (HADS) Nepali version was used to screen anxiety and depression among caregivers. ${ }^{8}$ It consists of 14 items; seven items for screening anxiety and seven items for screening depression. Each item has score range from 0 to 3 and maximum obtainable score is 21 each for anxiety and depression. Score from 0 to 7 is considered as 'normal', 8 to 10 as 'borderline case' and 11 to 21 as 'case of anxiety or depression. ${ }^{8}$

The ZBI-12 scale was forward and backward translated, then pretested among 15 participants before administration; internal consistency (Cronbach's alpha) was 0.773 , which was similar Persian version of tool. ${ }^{9}$ Internal consistency of the tool in original language is 0.81 . $^{10}$ 


\section{Data analysis}

Data were analyzed using SPSS for Windows, version 16.0 (SPSS Inc., Chicago, IL, USA). Descriptive statistics: mean, standard deviation (SD), median, and interquartile range (IQR) were calculated. Various factors that could be associated with caregiving burden were analyzed. Categorical data were analyzed with bivariate analysis and the factors that had $p$ value $\leq 0.2$ were entered into multinomial logistic regression model to find out the independent predictors. Similarly, the variables with continuous data were entered into linear regression model to find out the independent predictors of burden. Level of significance for all tests was set at 0.05 .

\section{Ethical consideration}

Ethical clearance was obtained from Institutional Review Committee. Informed consent was obtained from each participant.

\section{Results}

Out of 200 caregivers screened for eligibility, 94 were excluded from the study because of language barrier, underlying psychiatric conditions and not consenting to participate in the study. Remaining 106 participants were further interviewed to collect data. Mean age of caregivers was 34.64 years $(S D, 8.18)$. Female to male ratio was 2.5:1. Mean age of children was 104 months (SD, 59.17). Median age of onset of epilepsy was 36 months (IQR, 12-96). Median duration of epilepsy was 36 months (IQR, 12-84). Other socio-demographic and clinical characteristics are presented in Table 1. Majority of respondents were one of the parents and Hindus by religion. Almost two thirds of respondents were economically above poverty line. There were nearly equal proportions of children with focal and generalized seizures. Only $6.6 \%$ of children had unknown onset of seizures.

Anxiety and depression levels among caregivers of children with epilepsy are presented in Table 2. Anxiety and depression each were present in $6.6 \%$ of caregivers. Borderline anxiety was present in $7.5 \%$ and borderline depression was present in $8.5 \%$ caregivers. Among them, $5.6 \%$ participants had borderline anxiety and borderline depression both whereas $3.7 \%$ participants had anxiety and depression both.

Result of bivariate analysis for detecting association of caregiving burden with different variables as are presented in Table 3. Poorly controlled seizure and presence of comorbidities in children were sig-
Table 1. Socio-demographic and clinical characteristics of caregivers and children with epilepsy $(n=106)$

\begin{tabular}{|c|c|}
\hline Variable & Value \\
\hline \multicolumn{2}{|l|}{ Age of caregivers (years) } \\
\hline$\leq 34$ & $53(50.0)$ \\
\hline$>34$ & $53(50.0)$ \\
\hline \multicolumn{2}{|l|}{ Sex of caregivers } \\
\hline Female & 76 (71.7) \\
\hline Male & $30(28.3)$ \\
\hline \multicolumn{2}{|l|}{ Education of caregivers } \\
\hline Illiterate & $12(11.3)$ \\
\hline Up to 10th grade & $49(46.2)$ \\
\hline 11th grade and above & $45(42.5)$ \\
\hline \multicolumn{2}{|l|}{ Religion of caregivers } \\
\hline Hindu & $82(77.4)$ \\
\hline Christian & $9(8.5)$ \\
\hline Kirat & $9(8.5)$ \\
\hline Buddhist \& Muslim & $6(5.6)$ \\
\hline \multicolumn{2}{|l|}{ Ethnicity of caregivers } \\
\hline Janajati & $43(40.6)$ \\
\hline Bramhin/chhetri & $32(30.2)$ \\
\hline Madhesi & $21(19.8)$ \\
\hline Dalit/marginalized & $10(9.4)$ \\
\hline \multicolumn{2}{|l|}{ Family type } \\
\hline Nuclear & $59(55.7)$ \\
\hline Joint & $37(34.9)$ \\
\hline Extended & $10(9.4)$ \\
\hline \multicolumn{2}{|l|}{ Relationship with child } \\
\hline Mother & $68(64.2)$ \\
\hline Father & $29(27.4)$ \\
\hline Others & $9(8.4)$ \\
\hline \multicolumn{2}{|l|}{ Poverty* } \\
\hline Below poverty line & $38(35.8)$ \\
\hline Above poverty line & $68(64.2)$ \\
\hline \multicolumn{2}{|l|}{ Onset of seizure in children } \\
\hline Focal & $50(47.2)$ \\
\hline Generalized & $49(46.2)$ \\
\hline Unknown & 7 (6.6) \\
\hline \multicolumn{2}{|l|}{ Seizure control in children } \\
\hline Yes & $67(63.2)$ \\
\hline No & $39(36.8)$ \\
\hline \multicolumn{2}{|l|}{ Co-morbidities in children } \\
\hline No & $87(82.1)$ \\
\hline Yes & $19(17.9)$ \\
\hline \multicolumn{2}{|c|}{ Types of co-morbidities $(n=19)$} \\
\hline $\mathrm{CP}$ & 8 \\
\hline ID & 8 \\
\hline $\mathrm{ID}+\mathrm{CP}$ & 1 \\
\hline $\mathrm{ID}+\mathrm{ADHD}$ & 1 \\
\hline Wilson's disease & 1 \\
\hline
\end{tabular}

Values are presented as number (\%).

$C P$, cerebral palsy; ID, intellectual disability; $A D H D$, attention deficit hyperactive disorder.

*Classified as per definition of absolute poverty line by world bank (\$1.90 per person per day) in US doller. 
Table 2. Anxiety and depression levels among caregivers of children with epilepsy $(n=106)$

\begin{tabular}{lc}
\hline Category & Value \\
\hline No anxiety & $91(85.8)$ \\
Borderline anxiety* $^{*}$ & $8(7.5)$ \\
Anxiety $^{\dagger}$ & $7(6.6)$ \\
No depression & $90(84.9)$ \\
Borderline depression* $^{\star}$ & $9(8.5)$ \\
Depression $^{\dagger}$ & $7(6.6)$ \\
\hline
\end{tabular}

Values are presented as number (\%).

*5.6\% participantshad borderline anxiety and borderline depression both.

${ }^{3} 3.7 \%$ participants had anxiety and depression both. nificantly associated with caregiving burden. Other factors like age, gender, religion, ethnicity, level of education, economic status, relationship with child and type of seizure onset did not have statistical association with caregiving burden. Multinomial logistic regression analysis for predictors of burden is presented in Table 4. Poor seizure control and presence of co-morbidities independently predicted the high burden. The multiple linear regression analysis of variables (Table 5) showed that younger age of onset of epilepsy in child and higher depression score in caregiver had statistically significant positive and independent correlation with burden scores. Other factors like anxiety scores, duration of epilepsy in children and family size did

Table 3. Association of care giving burden with variables $(n=106)$

\begin{tabular}{|c|c|c|c|c|}
\hline \multirow{2}{*}{ Variable } & \multicolumn{3}{|c|}{ Frequency of Burden category } & \multirow{2}{*}{$p$-value } \\
\hline & No-mild & Mild-moderate & High & \\
\hline Age of caregivers (years) & & & & 0.134 \\
\hline$\leq 34$ & 28 & 14 & 11 & \\
\hline$>34$ & 34 & 15 & 4 & \\
\hline Gender of caregivers & & & & 0.500 \\
\hline Female & 44 & 18 & 14 & \\
\hline Male & 18 & 9 & 3 & \\
\hline Religion of caregivers & & & & 0.297 \\
\hline Hindu & 47 & 25 & 10 & \\
\hline Others & 15 & 4 & 5 & \\
\hline Education of caregivers & & & & NA \\
\hline Illiterate & 10 & 0 & 2 & \\
\hline Up to 10 class & 27 & 15 & 7 & \\
\hline 11 class and above & 25 & 12 & 8 & \\
\hline Economic status & & & & 0.756 \\
\hline Below poverty line* & 24 & 9 & 5 & \\
\hline Above poverty line* & 38 & 20 & 10 & \\
\hline Ethnicity of caregivers & & & & 0.081 \\
\hline Janajati & 30 & 7 & 6 & \\
\hline Others & 32 & 22 & 9 & \\
\hline Relationship with child & & & & 0.495 \\
\hline Mother & 37 & 20 & 11 & \\
\hline Others & 25 & 9 & 4 & \\
\hline Type of seizure & & & & 0.200 \\
\hline Focal onset & 33 & 12 & 5 & \\
\hline Generalized or unknown onset & 29 & 15 & 12 & \\
\hline Seizure control in child & & & & $<0.001$ \\
\hline Yes & 48 & 14 & 5 & \\
\hline No & 14 & 15 & 10 & \\
\hline Co-morbidities in child & & & & $<0.001$ \\
\hline Yes & 4 & 9 & 6 & \\
\hline No & 58 & 18 & 11 & \\
\hline
\end{tabular}

NA, not applicable.

*Classified as per definition of absolute poverty line by world bank ( $\$ 1.90$ per person per day) in US dollar. 
not have correlation with burden scores. Fig. 1 Illustrates the level of burden among caregivers. On ZBI-12 scoring, 59\% caregivers had no to mild burden, $27 \%$ had mild to moderate burden and $14 \%$ had high burden.

\section{Discussion}

Caregiver burden was assessed among caregivers of children with epilepsy attending child neurology clinic of a tertiary care medical university hospital of eastern Nepal. Mean age of caregivers was 34.64 years $(S D, 8.18)$. This data is comparable to that of similar studies conducted in Poland and Egypt. ${ }^{11,12}$ Similar to other studies conducted across different countries, most of the caregivers in this study were female and mothers of children with epilepsy. ${ }^{11-13}$ In Nepal, women are traditionally considered more responsible for bringing up children and caring for the family. This may be the reason for higher proportion of female caregivers in this study. Eleven percent of the caregivers were illiterate in present study. Illiteracy is one of the risk factors of poor health outcome. A systematic review of 73 articles concluded that low literacy was associated with poor health outcome. However, the review did not find conclusive results for association between burden and education. ${ }^{14}$ Similarly, there was no significant association of education levels and burden in present study. Majority (77.4\%) of the caregivers in this study were Hindus and many of them belonged to the ethnic group Janjati. Very few belonged to low caste ethnic groups such as Dalit and others. People belonging to low caste are usually financially underprivileged and likely to spend less for health, whereas people belonging to higher caste are economically stronger and likely to spend more for health. ${ }^{15}$ Since present study is a hospital based study, poor financial conditions might be the contributing factor for lower representation of Dalit and marginalized people coming to hospital. More than $55 \%$ of

$$
\text { a No to Mild } \square \text { Mild to Moderate } \square \text { High }
$$
$27 \%$

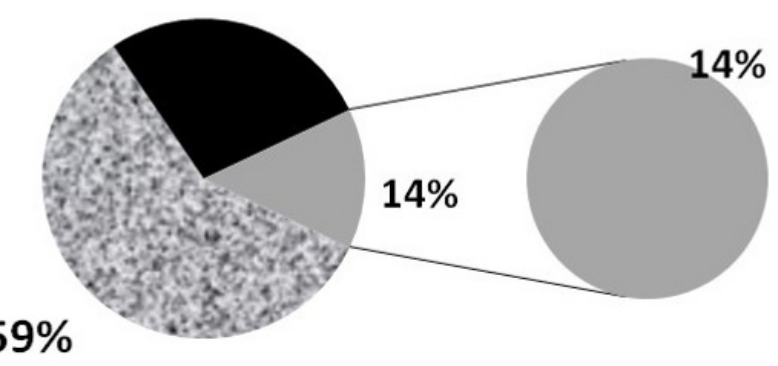

Figure 1. Level of burden among caregivers $(n=106)$.

Table 4. Multinomial logistic regression analysis for predictors of burden

\begin{tabular}{|c|c|c|c|c|c|c|}
\hline \multirow{2}{*}{ Predictor } & \multicolumn{3}{|c|}{ Mild to moderate burden } & \multicolumn{3}{|c|}{ High burden } \\
\hline & Exp. (B) & $95 \% \mathrm{Cl}$ & $p$-value & Exp. (B) & $95 \% \mathrm{Cl}$ & $p$-value \\
\hline Age $\leq 34$ years & 1.181 & $0.431-3.235$ & 0.747 & 2.857 & $0.779-10.476$ & 0.113 \\
\hline Ethnicity other than Janajati & 4.07 & $1.267-13.071$ & 0.018 & 1.449 & $0.391-5.377$ & 0.579 \\
\hline $\begin{array}{l}\text { Generalized of unknown } \\
\text { onset of seizure }\end{array}$ & 1.271 & $0.444-3.639$ & 0.654 & 3.489 & $0.818-14.884$ & 0.091 \\
\hline No seizure control in child & 3.083 & $1.071-8.875$ & 0.037 & 6.983 & $1.930-25.270$ & 0.003 \\
\hline $\begin{array}{l}\text { Presence of co-morbidities } \\
\text { in child }\end{array}$ & 7.164 & $1.801-28.493$ & 0.005 & 8.885 & $1.715-46.033$ & 0.009 \\
\hline
\end{tabular}

Compared with counterpart, reference category was no to mild burden.

Exp., exponentiation of $\mathrm{B} ; \mathrm{Cl}$, confidence interval.

Table 5. Multiple linear regression analysis for predictors of burden

\begin{tabular}{lcccc}
\hline Predictor & B & $t$-value & $95 \%$ Cl for B & $p$-value \\
\hline Family size & 0.095 & 0.386 & -0.394 to 0.584 & 0.701 \\
Anxiety in caregiver & -0.010 & -0.025 & -0.836 to 0.816 & 0.980 \\
Depression in caregiver & 1.217 & 3.036 & 0.422 to 2.013 & 0.003 \\
Age of onset of epilepsy in children & -0.049 & -3.268 & -0.078 to -0.019 & 0.001 \\
Duration of epilepsy in children & -0.015 & -0.830 & -0.50 to 0.021 & 0.408 \\
\hline
\end{tabular}

$\mathrm{Cl}$, confidence interval. 
participants were living in nuclear family. More than $38 \%$ of respondents were living under extreme poverty line. This indicates the need of further studies regarding economic burden in this group of people.

More than half of the children had focal onset of seizures and type of onset was not associated with care-giving burden. Majority (67\%) of the children had good seizure control. About 18\% children had co-morbidities. The most common co-morbidities were intellectual disability (ID) and cerebral palsy. Czyżewska et al. ${ }^{11}$ also found ID as the major co-morbidity among children with epilepsy. Epilepsy and ID share common aetiologies like metabolic disorders and brain injury. In some cases, epilepsy itself can cause temporary or permanent intellectual problems. ${ }^{16}$

More than half of the caregivers (58.5\%) had no to mild level of burden. Mild to moderate level of burden was present in $27.4 \%$ caregivers and remaining $13.9 \%$ had high level of burden. Higher proportion of caregivers comprised of female. In Nepal, females are expected to primarily take care of children and other household responsibilities. Therefore, they are used to cope with stress and may not feel burden in taking care of their children with chronic condition like epilepsy. That might be the reason for higher proportion of caregivers having no to mild burden. Czyżewska et al. ${ }^{11}$ also found low level of burden in $77 \%$ of caregivers in their study in Poland. In their study, medium level of burden was present in $21 \%$ and only $2 \%$ of caregivers had high level of burden. ${ }^{11}$ In a Nigerian study done among caregivers of adult patients with epilepsy, $51.9 \%$ of caregivers had high burden. ${ }^{1}$ The differences in levels of burden among different studies might be because of socio-economic and cultural differences, differences in availability of treatment options, age of patients and differences in resilience of people across different study settings.

In this study, about $7.5 \%$ of caregivers had borderline anxiety and $8.5 \%$ had borderline depression, whereas $6.6 \%$ caregivers had anxiety and depression each. Borderline anxiety and borderline depression both were present in $5.6 \%$ participants and $3.7 \%$ participants had anxiety and depression both. A Nigerian study also concluded anxiety and depression as common disorders among caregivers of children with seizure disorders. ${ }^{1}$ These results suggest that the caregivers of children with epilepsy are the hidden or "Forgotten" patients of anxiety and/or depression who also need psychiatric intervention. Mentally healthy individuals can provide better care to their children with chronic condition like epilepsy. Therefore, it is important to assess and manage caregivers' mental health conditions.
Burden was significantly higher among the caregivers whose children did not achieve good seizure control or had epilepsy associated co-morbidities. Hence poor seizure control and presence of comorbid conditions in children are likely to predict higher burden among caregivers. Abd El-Mouty and Salem ${ }^{12}$ also found that higher seizure frequency was associated with higher level of burden. Worries about unpredictable seizures, chronicity of illness and juxtaposition of work as well as child care might be the reasons for burden associated with poorly controlled seizures. Exploratory studies regarding causes of burden could further elaborate the reasons behind above results. In this study, the age of onset of epilepsy in children had significant negative correlation with burden scores. That means younger the age at onset of epilepsy, higher would be the level of burden. Other studies found that higher burden was associated with longer duration of epilepsy and care. ${ }^{1,11}$ Duration of epilepsy in children was not an independent factor correlating with burden among caregivers in present study. This difference in findings between present study and studies is probably because duration of epilepsy is dependent upon age of onset of epilepsy. They have not analysed age of onset of epilepsy. Age of onset of epilepsy and duration of epilepsy are interdependent and mutually exclusive. Hence duration of epilepsy was excluded by liner regression model and only age of onset of epilepsy was independent predictor of burden in present study. With younger age of onset, duration of caregiving becomes longer and care of children becomes more demanding physically and psychologically. This might increase stress on parents or carers. There was significant positive correlation between depression scores and burden scores in present study. A Nigerian study also concluded that psychiatric morbidity in caregivers is significantly associated with burden. ${ }^{1}$ It is obvious that with increasing burden caregivers are likely to have more depression.

There are some limitations in present study. Few subjects had to be excluded because of language barrier. Although the tools were translated in local Nepalese language, few subjects were not able to communicate in Nepalese language and their mother tongue was traditional ethnic language. Economic impact of epilepsy as a predictor of burden has not been directly explored in this study. In the areas like Nepal where healthcare insurance system is not well implemented, cost of medication can lead to adverse economic impact that may lead to further burden. The tools used for assessment of burden, anxiety and depression were screening tools, largely based on subjective expression from the participants. Further confirmation of diagnosis by objective assessment and meticulous use of diagnostic tools would have added more robustness in the study conclusion. 
Poorly controlled seizures and presence of co-morbidities in epileptic children are associated with higher level of burden in their caregivers. Burden tends to be higher in caregivers with younger age of onset of epilepsy. Depression in caregivers increases with increasing levels of burden. In conclusion, poorly controlled seizure, presence of associated comorbidities in children, younger age of onset of seizure and depression in caregivers are the important factors that predict burden among caregivers.

\section{References}

1. Babalola EO, Adebowale TO, Onifade P, Adelufosi AO. Prevalence and correlates of generalized anxiety disorder and depression among caregivers of children and adolescents with seizure disorders. J Behav Health 2014;3:122-7.

2. Karakis I, Cole AJ, Montouris GD, San Luciano M, Meador KJ, Piperidou C. Caregiver burden in epilepsy: determinants and impact. Epilepsy Res Treat 2014;2014:808421.

3. Awad AG, Voruganti LN. The burden of schizophrenia on caregivers: a review. Pharmacoeconomics 2008;26:149-62.

4. Sales E. Family burden and quality of life. Qual Life Res 2003;12 Suppl 1:33-41.

5. Haug MR. Elderly patients, caregivers, and physicians: theory and research on health care triads. J Health Soc Behav 1994;35:1-12.

6. Fisher RS, Cross JH, D'Souza $C$, et al. Instruction manual for the ILAE 2017 operational classification of seizure types. Epilepsia 2017;58:531-42.

7. Bédard M, Molloy DW, Squire L, Dubois S, Lever JA, O'Donnell M. The
Zarit Burden Interview: a new short version and screening version. Gerontologist 2001;41:652-7.

8. Risal A, Manandhar K, Linde M, Koju R, Steiner TJ, Holen A. Reliability and validity of a nepali-language version of the Hospital Anxiety and Depression Scale (HADS). Kathmandu Univ Med J (KUMJ) 2015;13:115-24.

9. Rajabi-Mashhadi MT, Mashhadinejad H, Ebrahimzadeh MH, GolhasaniKeshtan F, Ebrahimi H, Zarei Z. The Zarit Caregiver Burden Interview Short Form (ZBI-12) in spouses of veterans with chronic spinal cord injury, validity and reliability of the persian version. Arch Bone Jt Surg 2015;3: 56-63.

10. Gratão ACM, Brigola AG, Ottaviani $A C$, et al. Brief version of Zarit Burden Interview (ZBI) for burden assessment in older caregivers. Dement Neuropsychol 2019;13:122-9.

11. Czyżewska P, Talarska D, Grabowska-Fudala B, Michalak M, Bączyk G. Feeling of care burden in parents looking after children with epilepsy. Epileptologia 2011;19:91-7.

12. Abd El-Mouty SM, Salem NM. Burden and quality of life among caregivers to children with epilepsy. Am J Nurs Res 2019;7:817-23.

13. Abbas Z, Elseed MA, Mohammed IN. The quality of life among Sudanese children with epilepsy and their care givers. Sudan J Paediatr 2014;14:51-8.

14. Dewalt DA, Berkman ND, Sheridan S, Lohr KN, Pignone MP. Literacy and health outcomes: a systematic review of the literature. J Gen Intern Med 2004;19:1228-39.

15. Global South Development Magazine (GSDM). Poverty in Nepal: Causes and Consequences [Internet]. Kathmandu: GSDM, [cited 2019 Nov 3]. Available at: https://uww.gsdmagazine.org/poverty-in-nepal-causes-consequences/.

16. Besag FM. Childhood epilepsy in relation to mental handicap and behavioural disorders. J Child Psychol Psychiatry 2002;43:103-31. 